\title{
IMPORTANCE OF PROXIMAL ANGLE IN GENERATION OF ABNORMAL PLAQUE AT CORONARY BIFURCATION LESIONS
}

\author{
K. Deepti, MS Aditya
}

\section{ABSTRACT}

BACKGROUND: Changing of linear blood flow to turbulence at branching points predisposes to development of obstructive coronary lesions. We hypothesize that in addition to bifurcation angle (BA), proximal (PA) and third angle (TA) of branching site are important in generating more vertices of blood flow.

METHODS: 65 normal and 36 significantly diseased LAD D1, 72 normal and 27 significantly diseased LCX - OM , 73 normal and 16 significantly diseased RCA - PDA - PLV and 34 normal and 14 significantly diseased LMCA - LAD - LCX bifurcations were analyzed with QCA.

RESULTS: In LAD - D1 normal vs. significantly diseased bifurcations $B A$ and $P A$ were $78.2 \pm 13.2$ vs. $65.1 \pm 11.3(p<0.000)$ and $122.7 \pm 13.8$ vs. $131.6 .36 \pm 12.5(p<0.001)$ respectively. In $L C X$ - OM normal vs. significantly diseased bifurcations $B A$ and $P A$ were $76.8 \pm 13.6$ vs. $60.7 \pm 13.8(p=0.000)$ and $125.1 \pm 13.5$ vs. $137.8 \pm 12.8(p<0.000)$ respectively. In RCA - PDA - PLV normal vs. significantly diseased bifurcations $B A, P A$ and TA were $91.1 \pm 13.8$ vs. $71.5 \pm 15.9$ (p 0.004), $113.0 \pm 14.1$ vs. $128.4 \pm 20.2$ $(p=0.000), 118.2 \pm 21.7$ vs. $133.8 \pm 12.4(p=0.007)$ respectively. In LMCA -LAD - LCX normal vs. significantly diseased bifurcations $B A, P A$ and TA were $84.0 \pm 39.1$ vs. $73.0 \pm 17.6$ ( $p>0$. $32), 123.2 \pm 26.3$ vs. $115.3 \pm 30.4(p>0.38), 130.3 \pm 27.3$ vs. $137.5 \pm 33.5(p>0.45)$ respectively. There was a significant difference but no correlation between the angles in normal and diseased bifurcation segment. We derived logistic regression equations for predicting the disease in different coronary bifurcations.

CONCLUSION: In LAD - D1, LCX - OM and RCA - PDA $P L V$ bifurcations lesser the $B A$, greater the $P A$, were more likely to develop significant lesion, which was not true in LMCA - LAD - LCX bifurcation.

Key words : Bifurcation angle, proximal angle, Coronary artery disease.

Article received on 25 DEC 2015, published on 10 JAN 2016.

K. Deepti ${ }^{1}$, MS Aditya ${ }^{2}$

${ }^{1}$ Senior resident, Departments of Cardiology, NIMS, India

${ }^{2}$ Assistant Professor,

Corresponding author: K. Deepti,

Email: deepthi.kodati@gmail.com

\section{INTRODUCTION}

Bifurcation lesions constitute an important subset of coronary lesions, and successful management of these requires an understanding of the different bifurcation anatomical characteristics which can predispose to the development of these lesions [1,2]. Literature comparing differences in these characteristics (especially bifurcation and proximal angle) between those with significant and non-significant bifurcation lesions are not available so far. Thus the role of these in the generation of bifurcation lesions is poorly studied, so we wanted to conduct a study in this regard.

Previously some studies pointed out the importance of bifurcation angle (BA) in generation of coronary bifurcation lesions and also the role of the BA in choosing optimal intervention strategy. However their results were not universally applicable [1] . Probably this difference could be because of other parameters involved, specially proximal angle (PA) and third angle (TA). As coronary artery is a three dimensional structure, the angle between the side branch (SB) and proximal main vessel (PMV) is not simply BA subtracted from 180 degrees. Therefore a study of these bifurcation characteristics in both normal and diseased bifurcations is necessary to give further insight on the role of these factors in the generation of bifurcation lesions and determining optimal intervention strategy.

\section{MATERIALS AND METHODS}

It's a prospective open label double arm study, conducted in our institute between Jan and July 2012. Patients were recruited from cardiology department who had been admitted for coronary angiogram as per standard indications. Subjects with normal (or minimal CAD) coronary angiograms and coronary angiogram 
showing significant different bifurcation lesions were selected. All the demographic details of the subject including the risk factors and indication to CAG were recorded. Acute MI and/or cardiogenic shock subjects were excluded. The study protocol was approved by the NIMS Institutional Ethics Committee and all subjects gave written informed consent before enrollment.

Normal coronary bifurcation is a 3 dimensional structure. It has three angles. Bifurcation, proximal and third angle. BA is the angle between the distal main vessel (DMV) and the $\mathrm{SB}$; $\mathrm{PA}$ is the angle between the PMV and the SB. TA is the angle between the proximal and distal segment which may be a straight line in LADD1 and LCX-OM, but this is important in LMCA-LADLCX and RCA-PDA-PLV bifurcations (Fig 1). In previous studies importance was given to BA only in generation of bifurcation lesions.

Fig 1: Diagrammatic representation of different angles in bifurcation lesion.

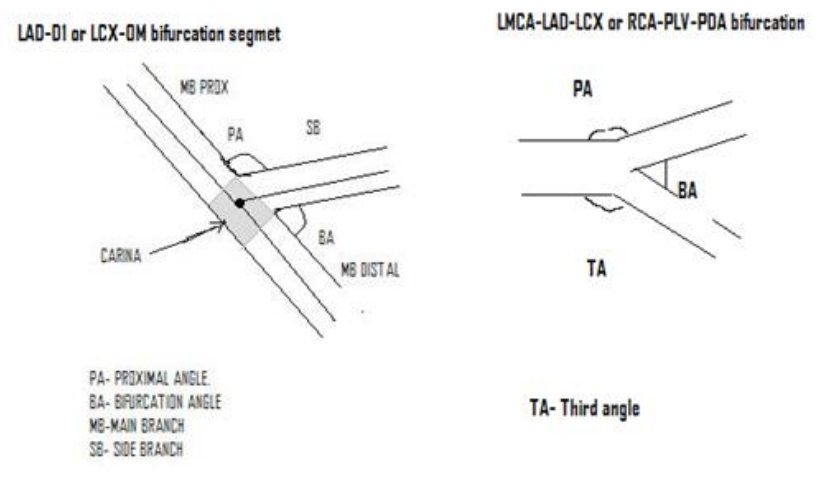

The coronary angiographic view in which the bifurcation is well delineated is chosen. Quantitative coronary angiography (QCA) is done with the help of the Seimens software provided in the Cath lab console. All the diameters are to be taken after initial calibration with the catheter size.

Different parameters related to bifurcation were studied and analyzed broadly in two subgroups-1) those with significantly diseased bifurcation 2) those with insignificant bifurcation or normal bifurcation coronary segments. Significant disease refers to luminal narrowing causing greater than 50\% luminal obstruction. Insignificant disease refers to mild disease causing less than $20 \%$ luminal narrowing. The different parameters studied were PMV reference vessel diameter (RVD), DMV RVD and SB RVD, PMV minimal luminal diameter (MLD), DMV MLD, SB MLD, BA, PA and TA (where is relevant). The large sized SBs were only studied in the case of bifurcations involving diagonals and OMs ( $\geq 2.5 \mathrm{~mm}$ diameter).

Four major bifurcation segments (LAD-D1, LCXOM, RCA-PDA-PLV and LMCA-LAD-LCX) can be classified as two major categories depending on the number of angles in the bifurcation segment. For LADD1 and LCX-OM bifurcation segment there are two angles, BA and PA. BA is the angle between DMV (either distal LAD or LCX) \& SB (D1 or OM) and PA is the angle between the PMV ( either proximal LAD or LCX) and SB (D1 or OM). In RCA-PDA-PLV and LMCALAD-LCX there is a third angle. In RCA-PDA-PLV the BA is between PDA \& PLV, PA is between distal RCA \& PLV, TA is the angle between the distal RCA and PDA. In LMCA-LAD-LCX the BA is between LAD \& LCX, PA is between distal LMCA \& LAD, TA is the angle between the distal LMCA \& LCX.

STATISTICAL ANALYSIS: Univariate analysis of categorical variables was performed with the Fisher's exact test and continuous variables were analyzed by Student's t-test. Correlations between parameters were evaluated by linear regression analysis. Differences were considered significant when $\mathrm{P}<0.05$. ANOVA test was done to see the effect of different angles in diseased bifurcation segment. Equations for probability of diseased bifurcation detection were derived from the binary logistic regression. Statistical analysis was performed using MINITAB 16 version.

\section{RESULTS}

73 normal (or minimal CAD) coronary angiograms and 93 coronary angiogram showing significant different bifurcation lesions were selected. Baseline demographic parameters are presented in Table 1.

Table 1: Risk factors details.

\begin{tabular}{|l|l|l|}
\hline Risk factors & $\begin{array}{l}\text { Normal bif. } \\
\text { Seg. (73) }\end{array}$ & $\begin{array}{l}\text { With bif. } \\
\text { Lesi.(93) })^{\#}\end{array}$ \\
\hline Hypertension & $32(43.8 \%)$ & $62(66.7 \%)$ \\
\hline Diabetes (type 2) & $26(35.6 \%)$ & $41(44.1 \%)$ \\
\hline Smoking & $9(12.3 \%)$ & $33(35.5 \%)$ \\
\hline Dyslipidemia & $16(21.9 \%)$ & $29(31.2 \%)$ \\
$\#=$ Bifurcation lesions of different vessels were taken from different pts.
\end{tabular}


As shown in the Table 2, atypical chest pain with the positive treadmill test was the common indication for CAG as we require relatively normal epicardial coronaries to compare with significantly diseased bifurcation segments.

Table 2: Type of presentation of patients in whom the CAG films were analyzed

\begin{tabular}{|l|l|}
\hline Type of presentation & No of cases (\%) \\
\hline Post MI angina & $09(5.4 \%)$ \\
\hline Unstable angina & $42(25.3 \%)$ \\
\hline Chronic stable angina & $42(25.3 \%)$ \\
\hline $\begin{array}{l}\text { Atypical chest pain with } \\
\text { positive treadmill test }\end{array}$ & $73(43.9 \%)$ \\
\hline
\end{tabular}

Details of bifurcation segments analyzed are mentioned in Table 3.

Table 3: Bifurcation segment details

\begin{tabular}{|l|l|}
\hline Bifurcation site & No \\
\hline LAD-D1 & \\
Normal Bif. Seg & 65 \\
Diseased Bif. Seg & 36 \\
\hline LCX-OM & \\
Normal Bifurcation segment & 72 \\
Diseased Bifurcation segment & 27 \\
\hline RCA-PDA-PLV & \\
Normal Bifurcation segment & 73 \\
Diseased Bifurcation segment & 16 \\
\hline LMCA-LAD-LCX & \\
Normal Bifurcation segment & 34 \\
Diseased Bifurcation segment & 14 \\
\hline
\end{tabular}

Bifurcation segments were divided into A \& B subgroups. Group A - Bifurcation segments with two important angles (that is BA \&PA- LAD-D1 \& LCX-OM bifurcations). Group B - Bifurcation segments with three important angles (that is BA, PA \& TA - LMCA-LADLCX \& RCA-PDA-PLV bifurcations). These different angles in group A (Table 4) and in group B (Table 5) in normal and diseased bifurcation segments were mentioned in Table 4 and 5.

In LAD D1, LCX - OM and RCA - PDA - PLV bifurcations it was observed that smaller the BA, and
Table 4: Bifurcation and proximal angles in normal and diseased bifurcation segments in Group A.

\begin{tabular}{|l|l|l|l|l|l|l|}
\hline $\begin{array}{l}\text { Bifurcation } \\
\text { site }\end{array}$ & BA & $\begin{array}{l}\text { EFD } \\
(95 \% \\
\text { CI })\end{array}$ & $\begin{array}{l}(\mathrm{T} \\
\text { value }) \\
\text { P value }\end{array}$ & PA & $\begin{array}{l}\text { EFD } \\
(95 \% \mathrm{CI})\end{array}$ & $\begin{array}{l}\text { Palue } \\
\text { value }\end{array}$ \\
\hline $\begin{array}{l}\text { LAD-D1 } \\
\text { Normal bif }\end{array}$ & $\begin{array}{l}78.2 \pm \\
13.2\end{array}$ & $\begin{array}{l}13.13 \\
(7.95,\end{array}$ & $\begin{array}{l}(5.03) \\
18.000\end{array}$ & $\begin{array}{l}122.7 \pm \\
13.8\end{array}$ & $\begin{array}{l}-8.87 \\
(-14.48,\end{array}$ & $\begin{array}{l}(-3.2) \\
0.002\end{array}$ \\
$\begin{array}{l}\text { Diseased } \\
\text { bif. }\end{array}$ & $65.1 \pm$ & 11.3 & & $131.6 \pm$ & $-3.36)$ & \\
\hline $\begin{array}{l}\text { LCX-OM } \\
\text { Normal bif. }\end{array}$ & 76.78 & 16.08 & $(5.23)$ & $125.1 \pm$ & -12.7 & $(-4.22)$ \\
& \pm 13.6 & $(9.97$, & 0.000 & 13.6 & $(-18.70$, & 0.000 \\
Diseased & $60.70 \pm$ & $22.19)$ & & $137.80 \pm$ & $-6.74)$ & \\
bif. & 13.8 & & & 12.8 & & \\
\hline
\end{tabular}

Foot note $: \mathrm{EFD}=$ Estimate For Difference, bif. = bifurcation.

larger the PA and more the incidence of significant bifurcation lesions. In LAD-D1 the BA alone was found to be more important, but in other two bifurcations other two angles were also important. Though some difference was observed in normal vs. diseased LMCA-LAD-LCX bifurcation, this was not statistically significant $(\mathrm{p}=0.32)$. If PA can be derived by subtracting BA from full circle than it is expected that BA and PA should be perfectly correlating negatively. In this study we did not find the correlation between BA and/or PA and/or TA in all four either normal or diseased bifurcations except normal LAD-D1 bifurcation. So our hypothesis that both BA and PA angle calculation is required to predict the disease of the vessel is acceptable.

Even though Univarient analysis showed that separately both BA $(p=0.000)$ and PA $(p=0.002)$ were statistically important in diseased LAD-D1 bifurcation, but in predicting the significant lesion at this bifurcation by binary logistic regression showed only importance of BA. R-Sq was $90.16 \%$ by ANOVA. Probability of disease in LAD- D1 bifurcation $=1 / 1+\mathrm{e}-\mathrm{Z}$, whereas $\mathrm{Z}=$ $10.95-0.14 *$ BA (Derived by binary logistic regression). Univarient analysis showed that separately both BA ( $\mathrm{p}=$ $0.000)$ and PA $(p=0.000)$ were statistically important in diseased LCX-OM bifurcation. R-Sq was $94.94 \%$ by ANOVA. Probability of disease in LCX-OM bifurcation $=1 / 1+\mathrm{e}-\mathrm{z}$, whereas $\mathrm{Z}=0.08$ * PA $-0.1 * \mathrm{BA}$ (Derived by binary logistic regression). Details of binary logistic 
Table 5: Details of bifurcation, proximal and third angles in normal and diseased bifurcation segments in Group B.

\begin{tabular}{|c|c|c|c|c|c|c|c|c|c|}
\hline Bifurcation site & BA & $\begin{array}{c}\text { EFD } \\
(95 \% \\
\mathrm{CI}) \\
\end{array}$ & $\begin{array}{c}\mathrm{P} \\
\text { value }\end{array}$ & PA & $\begin{array}{c}\text { EFD } \\
(95 \% \\
\mathrm{CI}) \\
\end{array}$ & $P$ value & TA & EFD $(95 \% \mathrm{CI})$ & $\begin{array}{c}\mathrm{P} \\
\text { value }\end{array}$ \\
\hline $\begin{array}{l}\text { LMCA-LAD- } \\
\text { LCX } \\
\text { Normal bif. } \\
\text { Diseased bif. }\end{array}$ & $\begin{array}{l}84.0 \pm 39.1 \\
73.0 \pm 17.6\end{array}$ & $\begin{array}{l}11.0 \\
(-11.0 \\
33.0)\end{array}$ & $\begin{array}{l}(1.01) \\
0.32\end{array}$ & $\begin{array}{l}123.2 \pm 26.3 \\
115.3 \pm 30.4\end{array}$ & $\begin{array}{l}7.8 \\
(-9.8 \\
25.39)\end{array}$ & $\begin{array}{l}(0.89) \\
0.38\end{array}$ & $\begin{array}{l}130.32 \pm 27.3 \\
137.5 \pm 33.5\end{array}$ & $\begin{array}{l}-7.14 \\
(-25.8,11.5)\end{array}$ & $\begin{array}{l}-0.77) \\
0.45\end{array}$ \\
\hline $\begin{array}{l}\text { RCA-PDA-PLV } \\
\text { Normal Bif. } \\
\text { Diseased bif. }\end{array}$ & $\begin{array}{l}91.1 \pm 13.8 \\
79.5 \pm 15.9\end{array}$ & $\begin{array}{l}11.59 \\
(3.81 \\
19.37)\end{array}$ & $\begin{array}{l}(2.96) \\
0.004\end{array}$ & $\begin{array}{l}113.0 \pm 14.1 \\
128.4 \pm 20.2\end{array}$ & $\begin{array}{l}-15.42 \\
(-23.8 \\
-7.03)\end{array}$ & $\begin{array}{l}(-3.7) \\
0.000\end{array}$ & $\begin{array}{l}118.2 \pm 21.7 \\
133.8 \pm 12.4\end{array}$ & $\begin{array}{l}-15.60 \\
(-26.81,-4.39)\end{array}$ & $\begin{array}{l}(-2.8) \\
0.007\end{array}$ \\
\hline
\end{tabular}

$\mathrm{EFD}=$ Estimate For Difference, bif. = bifurcation .

Table 6 : Results of Binary logistic regression analysis

\begin{tabular}{|c|c|c|c|c|c|}
\hline Bif. Type & Predictor & Co-efficient & P value & odds Ratio & $95 \%$ CIs \\
\hline LAD-D1 & \multicolumn{5}{|c|}{$\begin{array}{l}\text { Log-Likelihood }=-38.613, \\
\text { Test that all slopes are zero: } G=54.345, D F=2, P-\text { Value }=0.000\end{array}$} \\
\hline & Constant & 10.9477 & 0.001 & & \\
\hline & LAD-D1 BA & -0.144673 & 0.000 & 0.87 & $0.82-0.92$ \\
\hline & LAD-D1 PA & -0.0156837 & 0.447 & 0.98 & $0.95-1.03$ \\
\hline LCX-OM & \multicolumn{5}{|c|}{$\begin{array}{l}\text { Log-Likelihood }=-37.940, \\
\text { Test that all slopes are zero: } G=40.139, D F=2, P-\text { Value }=0.000\end{array}$} \\
\hline & Constant & -4.63076 & 0.148 & & \\
\hline & LCX-OM BA & -0.0995107 & 0.000 & 0.91 & $0.86-0.95$ \\
\hline & LCX-OM PA & 0.0796662 & 0.001 & 1.08 & $1.03-1.13$ \\
\hline $\begin{array}{l}\text { RCA-PDA- } \\
\text { PLV }\end{array}$ & \multicolumn{5}{|c|}{$\begin{array}{l}\text { Log-Likelihood }=-27.344, \\
\text { Test that all slopes are zero: } G=29.159, \mathrm{DF}=3, \mathrm{P}-\text { Value }=0.000\end{array}$} \\
\hline & Constant & -10.4631 & 0.015 & & \\
\hline & PDA-PLV BA & -0.0694749 & 0.007 & 0.93 & $0.89-0.98$ \\
\hline & RCA-PLV PA & 0.0786622 & 0.001 & 1.08 & $1.03-1.09$ \\
\hline & RCA-PDA TA & 0.0426265 & 0.036 & 1.04 & $1.00-1.09$ \\
\hline
\end{tabular}

Table 7 : Goodness-of-Fit Tests for logistic regression.

\begin{tabular}{|l|l|l|l|l|}
\hline Type of bifurcation & & Chi-square & DF & P value \\
\hline LAD-D1 & Hosmer-Lemeshow & 3.7453 & 8 & 0.879 \\
\hline & Pearson & 86.0735 & 98 & 0.800 \\
\hline LCX-OM & Hosmer-Lemeshow & 3.1047 & 8 & 0.928 \\
\hline & Pearson & 76.3522 & 96 & 0.930 \\
\hline RCA-PDA-PLV & Hosmer-Lemeshow & 14.9112 & 8 & 0.061 \\
\hline & Pearson & 79.8157 & 85 & 0.639 \\
\hline
\end{tabular}


regress (Table 6) and goodness of fit (Table 7) for different bifurcations were mentioned in Table $6 \& 7$. Univarient analysis showed that separately BA $(\mathrm{p}=$ $0.004)$, PA $(p=0.000)$ and TA $\quad(p=0.007)$ were statistically important in diseased RCA-PDA-PLV bifurcation. R-Sq was $91.05 \%$ by ANOVA. Probability of disease in RCA-PDA-PLV bifurcation $=1 / 1+\mathrm{e}-\mathrm{Z}$, whereas $\mathrm{Z}==0.079 * \mathrm{PA}+0.04 * \mathrm{TA}-10.46-0.07 * \mathrm{BA}$ (Derived by binary logistic regression).

\section{DISCUSSION:}

The original physical properties of blood flow at bifurcation points in vivo may be difficult to record, but an attempt was made by Peacock $J$ in vitro and by Sankaran S with simulation. Peacock et al presented empirical correlations for the onset of turbulence in pulsatile flow through a straight tube and 45 degrees Tbifurcation. Compared to pulsatile flow through the straight tube, the presence of flow separation within the 45 degrees T-bifurcation induced flow instabilities at lower values of the peak Reynolds number. So, they concluded that flow instabilities at coronary branch points may play an important role in atherogenesis [3]. Sankaran et al used a stochastic collocation method for uncertainty quantification and propagation in cardiovascular simulations. This analysis was performed on a carotid artery bifurcation and relevant hemodynamic features are extracted[4]. In vitro physical studies may not reflect the true in vivo bifurcation lesions, so we wanted to study these bifurcation characters by QCA. IVUS study done by Badak o et al on LAD-DI and LCX -OM bifurcations showed that Proximal segments demonstrated larger plaque volume than distal segments, despite similar percentages of plaque burden. Plaque volume accumulated opposite to the flow divider, especially in distal segments. The sidebranch take-off angle in the cross-sectional plane influenced the plaque distribution in bifurcation lesions. This study clearly gives message that that giving importance to only BA is not sufficient to know the extent of the disease burden in bifurcation lesion supporting our theory of calculating other angles [5]. Craiem D et al used 3D cylinders by MSCT to measure the BA. They found that LAD-LCX BAs were wider in the atherosclerotic group, but there are no studies using in other bifurcations [6] Soulis JV et al used a normal human left coronary artery bifurcation computational model to investigate the wall shear stress oscillation by applying non-Newtonian blood properties and phasic flow. They demonstrated that the lateral walls of the bifurcation, where low and oscillating wall shear stress is observed, are more susceptible to atherosclerosis. The systolic period, rather than the diastolic one, favors the development and progression of atherosclerosis[7] .

Mainly BA is given importance to decide intervention strategy, like compromization of the side branch[8]. Now a subgroup analysis of SYNTAX study used 3 dimensional BA analysis in LMCA bifurcation [9]. In this study they used proximal and distal BAs instead of PA and BA of the present study. The proximal BA (between LM and left circumflex [LCX]) and the distal BA (between left anterior descending and LCX) were computed in end-diastole and end-systole, both before and after PCI. Both proximal and distal angles are affected by cardiac motion; PCI modifies the distal angle. There is no clear difference in event rates across pre-PCI distal BA values. Present study shows that with all other risk factors and basic clinical profile matched, it can be observed that a smaller BA and the larger PA predisposes to the development of significant bifurcation lesions at least in most of the coronary bifurcations excluding LMCA-LAD-LCX bifurcation. Lack of significant relation with $\mathrm{PA}$ and $\mathrm{BA}$ in this position is not clearly known. BA was very widely differing between different patients. It could probably because of larger RVD and lesser vortices of flow. However other factors role requires a larger study in this regard will be able to clarify.

CLINICAL APPLICATION - With the probability equations derived from this study, we may able to predict the disease development in future for the pts who does not have the disease at present, but may develop latter if PA and BAs are suitable for development of the disease. Newer days CT coronary angiograms are done as screening procedure for detection of CAD, probably we can calculate angles in them and predict subsequent events.

STUDY LIMITATIONS- This study has limited number of subjects and some unexplained aspects (like in LMCA-LAD-LCX bifurcation none of the angles were associated with disease development) need to be 
addressed. The limitations of 2D QCA are expected, hence more accurate quantification of various bifurcation anatomical characteristics by 3D QCA software can be done. Applicability of the derived logistic regression equation for probability of detecting the diseases subsequently is also required. Limitation in logistic regression analysis was bifurcations from the different coronary arteries were taken as independent parameters and computed to derive the probability equations.

\section{CONCLUSIONS}

Though it's with a limited sample size some conclusions can be convincingly drawn. The proximal angles in a bifurcation in addition to bifurcation angle play an important role in the generation of coronary bifurcation lesions. In this regard it was observed that smaller bifurcation angle and larger proximal angle was noted in those with significant bifurcation lesions at LAD-D1, LCX-OM and RCA-PDA-PLV positions with significant difference from a statistical point of view. Such significance was not observed in LMCA-LAD-LCX bifurcation.

No studies in this regard were done earlier. Further studies in regard with larger population are needed. The influence of these anatomical factors on the outcomes of different strategies of bifurcation intervention will help to clarify the practical significance of this issue.

\section{REFERENCES}

1. Quantitative Angiographic Methods for Bifurcation Lesions: A Consensus Statement from the European Bifurcation Group .Catheterization and Cardiovascular Interventions 2009;73:258-266.

2. Stephen Saltissi, Michael M. Webb-Peploe, And D. John Coltart. Effect of variation in coronary artery anatomy on distribution of stenotic lesions. British Heart Journal 1979; 42:186-191.

3. Peacock J, Jones $\mathrm{T}$, Tock $\mathrm{C}$, Lutz R. An in vitro study on the effect of branch points on the stability of coronary artery flow. Med Eng Phys 1997:19(2):101-8.
4. Sankaran S, Marsden AL. A stochastic collocation method for uncertainty quantification and propagation in cardiovascular simulations. J Biomech Eng 2011; 133(3):03.

5. Badak $\mathrm{O}$, Schoenhagen $\mathrm{P}$, Tsunoda $\mathrm{T}$, Magyar WA, Coughlin J, Kapadia S, Nissen SE, Tuzcu EM. Characteristics of atherosclerotic plaque distribution in coronary artery bifurcations: an intravascular ultrasound analysis. Coron Artery Dis. 2003 ;14(4):309-16.

6. Craiem D, Casciaro ME, Graf $\mathrm{S}$, Glaser $\mathrm{CE}$, Gurfinkel EP, Armentano RL. Coronary arteries simplified with 3D cylinders to assess true bifurcation angles in atherosclerotic patients. Cardiovasc Eng. 2009 ;9(4):127-33.

7. Soulis JV, Giannoglou GD, Chatzizisis YS, Farmakis TM, Giannakoulas GA, Parcharidis GE, Louridas GE. Spatial and phasic oscillation of non-Newtonian wall shear stress in human left coronary artery bifurcation: an insight to atherogenesis. Coron Artery Dis. 2006 ;17(4):3518.

8. Vladimir Dzavik MD, Rajesh Kharbanda MB, Joan Ivanov PhD, Douglas J. Ing MD, Sanh Bui BSc, Karen Mackie RN, Rachael Ramsamujh RN, Alan Barolet MD, Leonard Schwartz MD, Peter H. Seidelin MB. Predictors of long-term outcome after crush stenting of coronary bifurcation lesions: Importance of the bifurcation angle. American Heart Journal 2006;152(4):762-769.

9. Chrysafios Girasis, Patrick W. Serruys, Yoshinobu Onuma, Antonio Colombo David R. Holmes, Jr, Ted E. Feldman, Eric J. Bass, Katrin Leadley, Keith D. Dawkins, and Marie-Claude Morice. 3Dimensional Bifurcation Angle Analysis in Patients With Left Main Disease A Substudy of the SYNTAX Trial (SYNergy Between Percutaneous coronary intervention with taxus and cardiac surgery. J. Am. Coll. Cardiol. Int. 2010;3;41-48 